\title{
Mycoplasma verecundum, a New Species Isolated from Bovine Eyes
}

\author{
By R. N. GOURLAY \\ Agricultural Research Council, Institute for Research on Animal Diseases, \\ Compton, Newbury RGI6 oNN, Berkshire \\ R. H. LEACH \\ Mycoplasma Reference Laboratory, Central Public Health Laboratory, \\ Colindale Avenue, London $\mathrm{NW}_{9}{ }_{5} \mathrm{HT}$ \\ AND C. J. HOWARD \\ Agricultural Research Council, Institute for Research on Animal Diseases, \\ Compton, Newbury RGI6 oNN, Berkshire
}

(Received I9 October 1973)

\begin{abstract}
SUMMARY
Two similar micro-organisms with the characteristics of the order Mycoplasmatales were isolated from the eyes of calves with conjunctivitis. Both isolates produced only a slight $\mathrm{pH}$ decrease in broth and did not ferment glucose or hydrolyse arginine or urea - hence they were almost undetectable by fluid cultures. Other biological characters included sterol dependence, indicative of the genus $\mathrm{Myco}$ plasma, production of 'film and spots', growth at low temperature $\left(20^{\circ} \mathrm{C}\right)$ or low $\mathrm{pH}(4 \cdot 7)$, and failure to reduce tetrazolium. The two strains were serologically indistinguishable from each other, but distinct from known bovine and other Mycoplasma species tested. Because of their distinct biological and serological characteristics they are proposed as forming a separate new species, Mycoplasma verecundum, with strain I07 (NCTCIOI45) as the type strain.
\end{abstract}

\section{INTRODUCTION}

The cultivation of mycoplasmas from the eyes of cattle with infectious bovine keratoconjunctivitis was first reported by Gourlay \& Thomas (I969). The mycoplasmas isolated included T-mycoplasmas, Mycoplasma bovirhinis, Acholeplasma laidlawii and other unidentified large-colony strains, some of which were subsequently allocated by Langford \& Leach (I973) to a new species, $M$. bovoculi, a classification based mainly upon study of strains isolated from cases of infectious bovine kerato-conjunctivitis in Canada (Langford \& Dorward, I969).

At Compton, several unidentifiable strains were isolated from the eyes of two affected animals during an apparently spontaneous outbreak of severe conjunctivitis that occurred in a group of calves being used for experimental studies. Details of the characterization of these strains are presented in this paper.

\section{METHODS}

Isolation procedure. Two swabs were taken from each eye of the calves examined, one swab being placed in glucose calf-serum (GS) broth (Gourlay \& Leach, 1970) and the other in urea broth (Gourlay, Mackenzie \& Cooper, 1970). After $\frac{1}{2}$ to I $h$ the swabs were removed 
and from each pair of inoculated broths a series of tenfold dilutions was made in $2 \mathrm{ml}$ volumes of the same medium. The dilutions were incubated at $37^{\circ} \mathrm{C}$ for up to 21 days and during this time any showing colour change were inoculated on the corresponding solid medium, which was then incubated at $37^{\circ} \mathrm{C}$ and subsequently examined for mycoplasma colonies.

Cultivation and purification of test strains. Strains isolated by the above procedure were usually subcultured in GS broth or agar, or in the horse serum broth or agar media of Hayflick (1965), but some tests were carried out on a medium (MRL agar) modified from the latter by use of heat-inactivated human or pig serum (10 \%, w/v) instead of horse serum and by inclusion of an extract of boiled horse blood (10 \%, v/v) and DNA $(0.002 \%, \mathrm{w} / \mathrm{v})$. Other media used in the testing of strains are described in the appropriate sections. Cultivation was carried out at $37^{\circ} \mathrm{C}$ except where otherwise indicated.

The isolates to be examined were cloned by picking single colonies from GS agar into GS broth. After incubation, the resulting broth culture was filtered through a $650 \mathrm{~nm}$ Millipore filter and dilutions of the filtrate plated on GS agar to produce well-separated single colonies. The whole procedure was then repeated twice more and, after the third single colony pick, subcultures were maintained as stock strains for further characterization.

Morphology. The morphology of the strains was examined by phase-contrast light microscopy of untreated broth cultures and by electron microscopy of culture deposits. For the latter purpose, organisms collected by centrifugation of broth cultures for $30 \mathrm{~min}$ at $1500 \mathrm{~g}$ were fixed in $4 \%$ glutaraldehyde and I \% osmium tetroxide, then embedded in Araldite and thin sections prepared for examination.

Filtration tests. Colony counts were performed on a $24 \mathrm{~h}$ broth culture before and after portions were filtered through Millipore membrane filters of 650,450 and $220 \mathrm{~nm}$ average pore diameter, at positive pressures of 34.39 to $68.78 \mathrm{kNm}^{-2}$.

Sterol requirement. The method used to determine the specific sterol requirement of the strains was based on that of Edward (1971) except that serum-free GS agar was used as the basal medium. To this was added bovine serum albumin $(0.5 \%, \mathrm{w} / \mathrm{v})$, palmitic acid (IO $\mu \mathrm{g} / \mathrm{ml})$ or cholesterol $(20 \mu \mathrm{g} / \mathrm{ml})$, each being tested both alone and in combination with the other substances.

Sensitivity to sodium polyanethol sulphonate and to digitonin, properties usually reflecting sterol-dependence, was determined on MRL agar by the paper disc inhibition method described by Freundt et al. (1973).

Biochemical tests. Fermentation of carbohydrates was tested by inoculation of the test strains into glucose-free GS broth plus I $\%(w / v)$ of the test carbohydrate. Cultures were examined during 2 weeks' incubation for colour $(\mathrm{pH})$ change, as compared with inoculated controls of the same medium without carbohydrate. Tests for hydrolysis of arginine or urea were made in glucose-free GS broth plus I \% (w/v) of either metabolite and with the $\mathrm{pH}$ value appropriately adjusted (Gourlay et al. 1970). The growth of the test strains and their ability to hydrolyse urea were also tested in the modified urea broth (U2 broth) described by Howard \& Gourlay (1973).

Tetrazolium reduction was examined in GS broth or agar containing triphenyl tetrazolium chloride $(0.02 \%, \mathrm{w} / \mathrm{v})$. The tetrazolium agar tests were incubated aerobically (Leach, 1973).

$D N A$ base composition. DNA was extracted by the method of Marmur (196I) and the base composition was estimated from the 'melting temperature' $\left(T_{m}\right)$ in saline citrate (Marmur \& Doty, 1962) and also by buoyant density (Black, Christiansen \& Askaa, 1972), using DNA from Escherichia coli strain B (Sigma) as reference material with an assumed buoyant density of $\mathrm{I} \cdot 7 \mathrm{I} / \mathrm{g} / \mathrm{cm}^{3}$. The DNA extractions and base composition estimations 
were carried out by Mr L. R. Hill $\left(T_{m}\right)$ and Dr D. J. Garwes and Mr D. Pocock (buoyant density).

Serology. Rabbit antiserum was prepared, as described by Howard \& Gourlay (1972), against strains 107 and 108 after these had been cloned as described above. The organisms were grown in a modified GS liquid medium in which Hartley's digest broth and calf-serum were replaced by rabbit meat infusion and $10 \%$ rabbit-serum respectively.

Strains were examined serologically by the growth inhibition technique (Clyde, 1964), by the metabolism inhibition technique (Taylor-Robinson, Purcell, Wong \& Chanock, I966), and by the indirect-immunofluorescence technique of Rosendal \& Black (1972) using fluorescein-labelled anti-rabbit serum (Nordic Diagnostics, Fraberg Ltd). Although neither strain 107 nor 108 caused breakdown of arginine, urea or carbohydrates or possessed any other specific biochemical property (see Results) upon which metabolism inhibition tests could be based, they nevertheless produced in broth a very slight acidification that could be inhibited by specific antiserum. It therefore proved possible to carry out metabolism inhibition tests with these strains using media and methods described for other acid-producing mycoplasmas (Taylor-Robinson et al. 1966), except that tests had to be read when a colour change equivalent to only about $-0.3 \mathrm{pH}$ unit (the maximum obtained with these strains) had occurred in the inoculated controls without antiserum. Guinea pig serum was not required for homologous reactions and was not included for tests against other antisera. The metabolism inhibition tests with other mycoplasmas were carried out as described elsewhere (Leach, 1973).

\section{RESULTS}

Isolation of mycoplasma from calf eyes

Two swabs were taken from each eye of a three-week-old calf (calf I08) showing signs of conjunctivitis and two days later similar samples were taken from a $4 \frac{1}{2}$-week-old calf (calf I07) with severe conjunctivitis. The swabs were transferred to GS broth and urea broth from which further dilutions in the same media were subsequently prepared. No colour change occurred in the urea broths but a faint acidity developed in the lower GS broth dilutions. In the case of calf 108 , the colour change was first noticed in the $10^{-1}$ and $10^{-2}$ dilutions after 5 days (but may have been present earlier) and was also produced by one of the two eye samples at $10^{-3}$ after 9 days. The swabs from calf 107 produced detectable colour changes at $10^{-1}$ to $10^{-3}$ after 3 days and drops from the $10^{-2}$ and $10^{-3}$ dilutions plated on GS agar produced a heavy growth of typical (' fried-egg') mycoplasma colonies (see next section and Fig. I) after 2 days of incubation at $37^{\circ} \mathrm{C}$. No colonies were obtained when the calf 108 samples showing colour change were plated.

Two weeks after the first swabs were taken, conjunctivitis was still present in both calves and further similar samples were taken from each animal. On this occasion the slight acid colour change in GS broth occurred to the ${ }^{10^{-6}}$ dilution in the case of calf 108 and to the $1^{10^{-4}}$ for calf 107 after 4 days of incubation. In both cases, inoculation of GS agar plates with broth dilutions showing colour change produced typical mycoplasma colonies. The cultures obtained from one of the broth dilutions $\left(\mathrm{IO}^{-2}\right)$ from each calf were subcultured further and were then maintained as stock cultures designated strains 107 and 108 respectively. These were cloned by single colony picking (see Methods) before their properties were examined further. 


\section{Properties of strains 107 and 108}

Growth and cultural characteristics. During primary isolation of these strains, their growth was indicated only by the very slight colour change (equivalent to a $\mathrm{pH}$ decrease of about 0.3 unit) that they produced in GS broth and their growth in the lower dilutions was detectable after 3 to 4 days at $37^{\circ} \mathrm{C}$. After several subcultures of the test strains, their $\mathrm{pH}$ effects remained the same but their growth was somewhat faster and was also accompanied by a slight increase in opacity of the GS broth.

These strains also grew readily on GS agar, in Hayflick-type broth or agar, in the modified urea (U2) broth or T-mycoplasma solid medium (Gourlay, Brownlie \& Howard, 1973) and also on MRL agar. Growth in $\mathrm{U}_{2}$ broth was accompanied by slight granular opacity but no colour change. On T-mycoplasma solid medium with adjusted $\mathrm{pH}$, colonies appeared

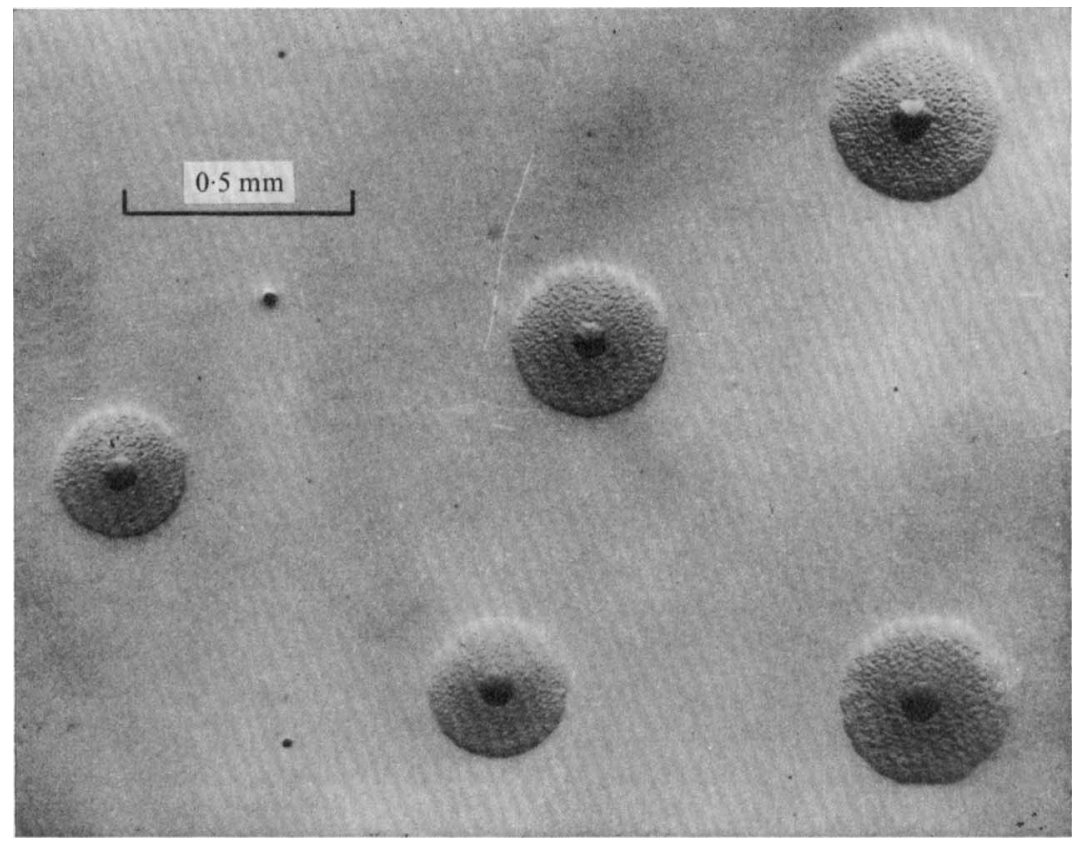

Fig. I. Colonies of strain 107 on T-mycoplasma solid medium. Oblique transmitted light.

between $\mathrm{pH} 4.7$ and $\mathrm{pH} 7.8$ (the range tested), with an optimum at $\mathrm{pH} 6$ as indicated by colony size (maximum about $0.5 \mathrm{~mm}$ ) and time for maximal growth of colonies. Growth on agar media occurred equally well under aerobic conditions or in an atmosphere of $5 \% \mathrm{CO}_{2}$ in nitrogen and the colonies produced had the centred ('fried-egg') form characteristic of mycoplasmas, with downgrowth into the medium (Fig. I). Colonies on GS agar with $5 \%$ ox blood incubated in $5 \% \mathrm{CO}_{2}$ in nitrogen, produced a surrounding area of $\beta$-haemolysis in the medium.

Reversion studies. The GS medium contained approximately I000 i.u. benzyl penicillin $/ \mathrm{ml}$ and $0.025(\mathrm{w} / \mathrm{v})$ thallous acetate. When each strain was serially subcultured five times on GS agar free from both these inhibitors, there was no colonial or cultural evidence of reversion to bacterial forms.

Morphology and staining characters. Under phase-contrast microscopy, unfixed organisms 
of strains 107 and 108 appeared highly pleomorphic, with coccoid bodies, ring forms and branched filaments. The organisms were Gram-negative and stained poorly with counterstain. Electron microscopy at low magnification (Fig. 2a) confirmed their pleomorphism but, as with most other mycoplasmas, most particles seen in a single thin section were round or oval in form with an average diameter of the order of $500 \mathrm{~nm}$. At higher magnification, individual bodies were seen to be bounded by a single triple-layered unit membrane (Fig. $2 b$ ) and there was no morphological evidence of a cell wall.

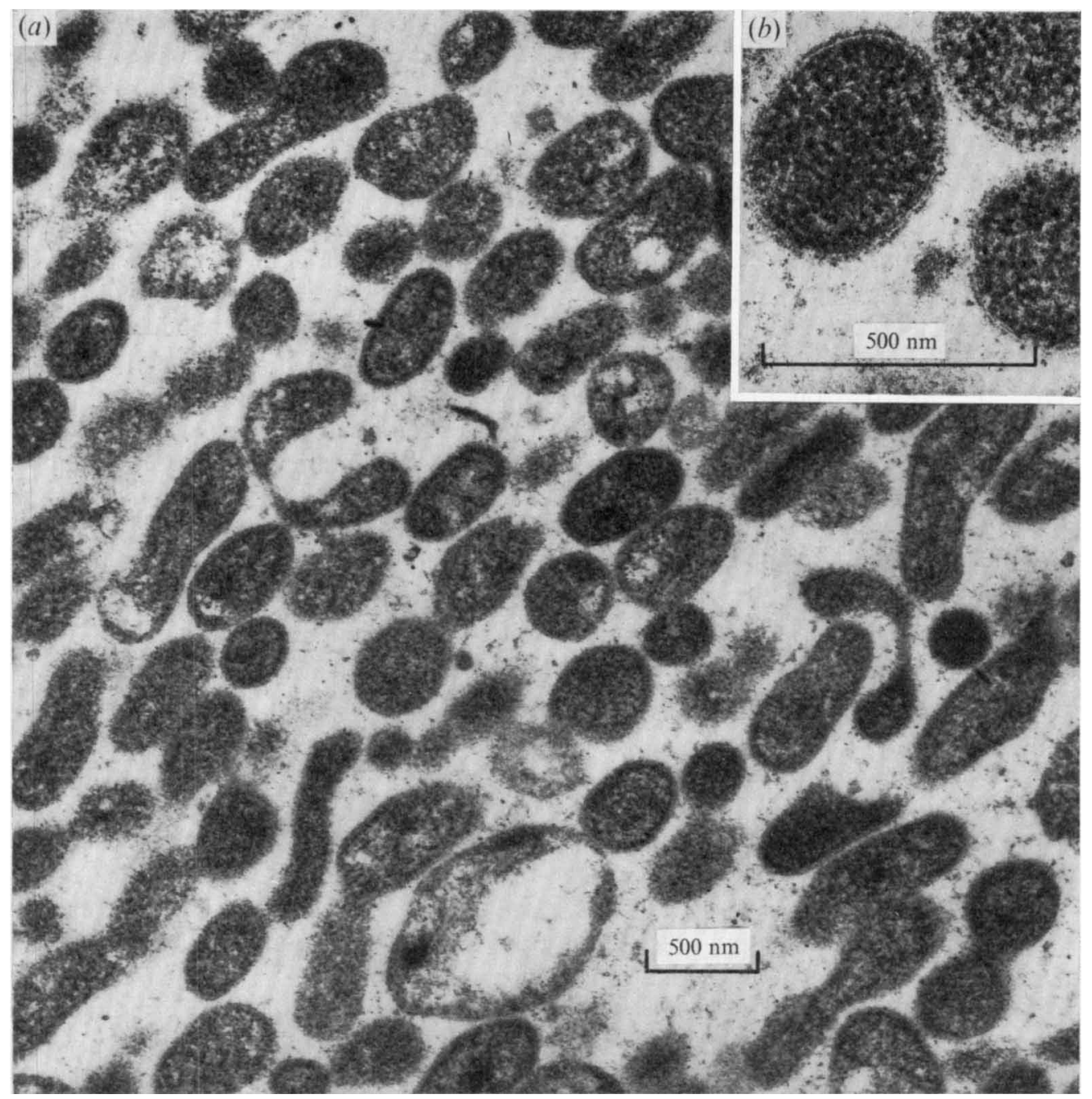

Fig. 2. Electron micrographs of thin-section preparations of centrifuged culture deposit of strain 107.

Filtration studies. A culture of strain 107 contained $8.4 \log _{10}$ colony-forming units $/ \mathrm{ml}$ before filtration and after passage of separate portions through membrane filters of $650 \mathrm{~nm}$, $450 \mathrm{~nm}$ and $220 \mathrm{~nm}$, this count was decreased by $\mathrm{I} \cdot 5,4.8$ and $>7.0 \log$ units, respectively. Filtration of a culture of a recognized species, Mycoplasma bovirhinis, with an initial count of $9 \cdot 2 \log$ units $/ \mathrm{ml}$, caused decreases of $0 \cdot 3, \mathrm{I} \cdot 3$ and $6 \cdot 5 \log$ units, respectively, for the corresponding filter. 
Biochemical characteristics. When incubated in glucose-free GS broth, strains 107 and I08 produced only a very slight fall in $\mathrm{pH}$ of about 0.3 unit as compared with uninoculated incubated medium. A similar degree of acidification was produced in the same broth containing either glucose or any of the following carbohydrates (see Methods): fructose, lactose, maltose, sucrose, arabinose, adonitol, dulcitol, mannitol, inositol, xylose, glycerol, sorbitol, trehalose, raffinose, galactose, sorbose, cellobiose, melibiose, melesitase, amygdalin, mannose and rhamnose. The results indicated that none of these carbohydrates was attacked by the test strains.

Neither strain reduced tetrazolium in broth culture or on solid medium incubated aerobically. Although both strains grew well in arginine broth and both of the urea-containing broths (see Methods), neither strain produced any appreciable $\mathrm{pH}$ change in these media.

Both strains produced 'film and spots' after 2 days on horse-serum agar plus $10 \%$ egg yolk extract (Fabricant \& Freundt, 1967), but only after prolonged incubation on horseserum agar and MRL agar.

Sterol requirement. Strains 107 and 108 failed to grow on the basal sterol-free agar but grew well on this medium when calf serum $(20 \%, \mathrm{v} / \mathrm{v})$, or cholesterol plus bovine serum albumin, or cholesterol plus bovine serum albumin plus palmitic acid were added to it (see Methods). They did not grow on the sterol-free agar plus any of the combinations of the latter substances that omitted either cholesterol or bovine serum albumin, or both. The results indicated that the serum requirement of these strains can be satisfied by cholesterol in the presence of bovine serum albumin and that a fatty acid (palmitic acid) is not required. As with most other sterol-dependent mycoplasmas (Freundt et al. 1973), growth of strains 107 and 108 on agar was completely inhibited in disc inhibition tests by $1.5 \%$ digitonin and by $20 \%$ sodium polyanethol sulphonate; 5 and $10 \%$ sodium polyanethol sulphonate caused partial inhibition.

Temperature requirements. On GS agar, strains 107 and 108 grew well at $37^{\circ} \mathrm{C}$ and nearly as rapidly at $30^{\circ} \mathrm{C}$. They also grew at 25,22 and $20^{\circ} \mathrm{C}$, but progressively more slowly. Development of visible colonies required II days incubation at $20^{\circ} \mathrm{C}$ but less than $24 \mathrm{~h}$ at $37^{\circ} \mathrm{C}$.

DNA base composition. The G-C ratio $(\% \mathrm{G}+\mathrm{C})$ was approximately 27 by the $T_{m}$ method and $29 \cdot 2$ by buoyant density. As a control, the G-C ratio obtained by buoyant density of the T960 strain of T-mycoplasma was $27 \cdot 4$. This compares well with the figure of $27 \cdot 1$ published by Black et al. (1972).

Serological studies. Antisera prepared in rabbits against strains 107 and 108 were tested against recognized mycoplasma species and cross-tests were also carried out with the test strains against antisera to bovine and other mycoplasmas.

Growth inhibition tests. Antisera to strains 107 and 108 inhibited growth of both strains in disc growth-inhibition tests, giving a clear inhibition zone of 2 to $5 \mathrm{~mm}$ diam. in repeated tests. These sera gave negative results against each of the recognized bovine mycoplasmas (Table 6 in Leach, 1973) and also against $M$. agalactiae subsp. agalactiae.

Metabolism inhibition tests. The tests with strains 107 and 108 were carried out on the basis of the colour change that was produced by each strain in broth and which could be inhibited by specific antiserum. However, since this colour change was very faint, the reading of the tests and assessment of titres was difficult and to some degree subjective, so that the titres recorded could be regarded only as approximate.

Strains 107 and 108 gave similar results in the metabolism inhibition tests (Table I). However, for both antisera, the titres obtained using 108 as antigen were less than those 
Table I. Results of cross-tests, by the metabolism inhibition (m.i.) and immunofluorescence (i.f.) techniques, between strains 107 and 108 and recognized bovine mycoplasma species

Titrest of antisera to the listed species tested against strains:

Species (and strain)
Mycoplasma mycoides
subsp. mycoides (PGI)
M. bovigenitalium
(PGI $)$
M. bovirhinis (PG43)
M. agalactiae subsp.
bovis (Donetta)
M. agalactiae subsp.
agalactiae (PG2)*
M. dispar (462/2)
M. bovoculi $(\mathrm{MI} 65 / 69)$
Mycoplasma sp. (group
7. N29)
M. arginini (G230)
M. alkalescens (DI2)
Acholeplasma
laidlawii $(\mathrm{PG} 8)$
A. modicum (Squire)
A. axanthum (BI07 PA)
Strain I07
Strain I08

Titres of antisera to strains 107 and 108 tested against the listed species:

\begin{tabular}{|c|c|c|}
\hline $\begin{array}{c}107 \\
\text { (m.i. test) }\end{array}$ & $\begin{array}{c}108 \\
\text { (m.i. test) }\end{array}$ & $\begin{array}{c}107 \\
\text { (i.f. test) }\end{array}$ \\
\hline$<$ IO & $<$ IO & $<20$ \\
\hline$<10$ & $<$ IO & $<20$ \\
\hline$<10$ & $<$ ro & $<20$ \\
\hline$<\mathrm{IO}$ & $<10$ & $<20$ \\
\hline$<$ IO & IO & Not tested \\
\hline$<$ IO & $<$ IO & $<20$ \\
\hline$<$ IO & $<$ IO & $<20$ \\
\hline$<$ IO & $<10$ & $<20$ \\
\hline$<$ IO & $<$ IO & $<20$ \\
\hline$<10$ & $<10$ & $<20$ \\
\hline$<10$ & $<\mathrm{IO}$ & $<20$ \\
\hline$<$ IO & $<$ IO & $<20$ \\
\hline$<$ IO & $<$ IO & Not tested \\
\hline $\begin{array}{c}\text { I } 280-2560 \\
40-320\end{array}$ & $\begin{array}{c}640-5120 \\
40-160\end{array}$ & $\begin{array}{l}640 \\
640\end{array}$ \\
\hline
\end{tabular}

* This is not a bovine mycoplasma but has been included for comparative purposes (see text).

$\uparrow$ Reciprocal of highest dilution of antiserum that inhibited metabolism or produced fluorescence.

NoTE: The source of antisera and their homologous titres are as listed by Landford \& Leach (1973).

$\ddagger 107$ only: 108 antiserum not tested.

Table 2. Recognized acid-producing species of Mycoplasmatales whose antisera* gave negative results $\dagger$ when tested against strain 107 in metabolism inhibition and immunofluorescence tests

Species

Mycoplasma pneumoniae
M. fermentans
M. pulmonis
M. neurolyticum
M. mycoides subsp. capri
M. ovipneumoniae
M. canis
M. gallisepticum
M. synoviae
M. anatis
M. hyorhinis
M. suipneumoniae
M. felis
Acholeplasma granularum

Strain

FH
PGI 8
880
KSA
PG3
M333/69
PGI4
PG3I ( $\times 95)$
WVUI 853 and Lasswade
I340
BTS7
J
Co
BTS39

* The sources of these antisera and their homologous titres are listed by Langford \& Leach (I973), except for the additional rabbit antiserum prepared at Colindale against a locally-isolated strain (M333/69) of $M$. ovipneumoniae.

$\dagger$ Titres of $<20$. 
obtained with 107. Further metabolism inhibition tests were carried out with strain 107 against antisera to all the recognized bovine mycoplasma species, together with $M$. agalactiae subsp. agalactiae whose main biochemical properties are similar to those of the test strains. The type strains of these species were also tested against the antisera to strains 107 and 108 (Table I); there was no appreciable cross-reactivity between strain 107 and the other mycoplasmas tested. Strain 107 was also tested by metabolism inhibition, with negative results, against available antisera to the other recognized acid-producing mycoplasmas and acholeplasmas listed in Table 2.

Immunofluorescence tests. Both the test strains gave high titres (640) in immunofluorescence tests against the antisera to these two strains, but gave negative results in tests against antisera to recognized bovine mycoplasmas and $M$. agalactiae subsp. agalactiae (Table I), and against antisera for the other species shown in Table 2.

\section{DISCUSSION}

Mycoplasmas with similar cultural properties were cultivated on two separate occasions from the eyes of two calves with conjunctivitis and strains 107 and 108 represent the cultures obtained from each animal on the second occasion. Further attempts to find similar organisms in the eyes of cattle at Compton have so far failed, but in view of the minimal colour $(\mathrm{pH})$ changes produced by these organisms in broth, their detection by this method is likely always to be difficult, particularly when other mycoplasmas are also present in the eyes.

The properties of strains 107 and 108 (see Results) satisfy the general requirements for their inclusion within the order Mycoplasmatales (Subcommittee on the Taxonomy of Mycoplasmatales, 1972). This conclusion is based on their characteristic morphology (including lack of cell wall), their colonial form (with characteristic downgrowth into the agar), their filtrability through a $450 \mathrm{~nm}$ membrane, their failure to revert to bacterial forms when bacterial inhibitors (i.e. penicillin and thallous acetate) were omitted from the medium, their inhibition by specific antiserum in the absence of complement, and their characteristically low DNA base composition, in the region of 27 to $29 \% \mathrm{G}+\mathrm{C}$, as determined for strain 107.

The inability of the test strains to grow in serum-free medium and their specificallydemonstrated requirement for sterol (cholesterol) determine that they should be classified within the family Mycoplasmataceae and genus Mycoplasma, a conclusion consistent with their sensitivity to sodium polyanethol sulphonate and digitonin (Freundt et al. 1973). The ability of the test strains to produce appreciable growth on agar at temperatures around $20{ }^{\circ} \mathrm{C}$ is unusual for a Mycoplasma species, but is not unique (e.g. Mycoplasma sp., group 7; see Leach, 1973). Their ready growth at a $\mathrm{pH}$ value as low as 4.7 is a property shared with the T-mycoplasmas from which, however, they are clearly differentiated by their colony size and inability to hydrolyse urea.

With regard to classification within the genus Mycoplasma, strains 107 and 108 resemble only $M$. bovigenitalium and $M$. agalactiae subsp. agalactiae and subsp. bovis (Leach, 1973) amongst recognized large-colony Mycoplasma species, in being unable to produce acid from carbohydrates and also unable to hydrolyse arginine. However, unlike the above three mycoplasmas, strains 107 and 108 produced only a very slight $\mathrm{pH}$ change in broth and were also able to grow on agar at lower temperatures. Their inability to reduce tetrazolium also tends to distinguish them from the two $M$. agalactiae subspecies and from some strains of $M$. bovigenitalium (Leach, 1973). The results of the serological studies confirm that strains 107 and 108, though indistinguishable from each other, are distinct from M. agalactiae and 
M. bovigenitalium and from other recognized bovine mycoplasmas. Additional serological tests against most of the acid-producing (fermentative) Mycoplasma species listed by Edward \& Freundt (1973) were also negative.

In view of their distinctive biological and serological properties, strains 107 and 108 must be regarded as representing a new Mycoplasma species for which we propose the name Mycoplasma verecundum. The specific epithet (verecundum: Latin adjective in the neuter meaning free from extravagence, shy or unobtrusive) alludes to this organism's lack of obvious biochemical characteristics, such as ability to break down carbohydrates, arginine or urea, and to its consequent liability to remain unnoticed. Strain 107, which has been examined in greater detail, is designated the type strain of $M$. verecundum and a culture has been deposited in the National Collection of Type Cultures, London, where it is available as NCTCIOI 45 .

The significance of this new Mycoplasma species in the aetiology of bovine eye infections is unknown and elucidation of this question will depend on inoculation experiments and on the success of further attempts to isolate strains of this organism from such conditions.

We thank Mr L. R. Hill (National Collection of Type Cultures), Dr D. J. Garwes and Mr D. Pocock (Institute for Research on Animal Diseases, Compton) for carrying out the base composition estimations, $\mathrm{Mr} \mathrm{L}$. H. Thomas for collecting the eye swabs, Mr B. France for the electron micrographs, Mr I. Jebbett for the photographs and Miss S. G. Wyld, Miss J. Wren and Miss E. A. Coleman for technical assistance.

\section{REFERENCES}

Black, F. T., Christiansen, C. \& AskaA, G. (1972). Genome size and base composition of deoxyribonucleic acid from eight human T-mycoplasmas. International Journal of Systematic Bacteriology 22, 24I-242.

Clyde, W. A. (1964). Mycoplasma species identification based upon growth inhibition by specific antisera. Journal of Immunology 92, 958-965.

EDWARD, D. G. ff. (I97I). Determination of sterol requirement for Mycoplasmatales. Journal of General Microbiology 69, 205-210.

EdWARD, D. G. ff. \& Freundt, E. A. (1973). Type strains of species of the order Mycoplasmatales, including designation of neotypes for Mycoplasma mycoides subsp. mycoides, Mycoplasma agalactiae subsp. agalactiae and Mycoplasma arthritidis. International Journal of Systematic Bacteriology 23, 55-6r.

FABricANT, J. \& FREUNDT, E. A. (1967). Importance of extension and standardization of laboratory tests for the identification and classification of Mycoplasma. Annals of the New York Academy of Sciences I43, 50-58.

Freundt, E. A., Andrews, B. E., Ernø, H., Kunze, M. \& Black, F. T. (1973). The sensitivity of Mycoplasmatales to sodium-polyanetholsulphonate and digitonin. Zentralblatt für Bakteriologie, Parasitenkunde, Infektionskrankheiten und Hygiene 225, I04-I 12.

Gourlay, R. N., Brownlie, J. \& Howard, C. J. (I973). Isolation of T-mycoplasmas from goats, and the production of subclinical mastitis in goats by the intramammary inoculation of human $\mathrm{T}$-mycoplasmas. Journal of General Microbiology 76, 25 I-254.

Gourlay, R. N. \& LeACH, R. H. (1970). A new mycoplasma species isolated from pneumonic lungs of calves (Mycoplasma dispar sp.nov.). Journal of Medical Microbiology 3, I I I-I 23.

Gourlay, R. N., Mackenzie, A. \& Cooper, J. E. (1970). Studies of the microbiology and pathology of pneumonic lungs of calves. Journal of Comparative Pathology 8o, 575-584.

Gourlay, R. N. \& Thomas, L. H. (I969). The isolation of large colony and T-strain mycoplasmas from cases of bovine kerato-conjunctivitis. Veterinary Record 84, 4I6-4I7.

Hayflick, L. (1965). Cell cultures and mycoplasmas. Texas Reports on Biology and Medicine 23 (S I), 285-303.

Howard, C. J. \& Gourlay, R. N. (1972). Serology of bovine T-mycoplasmas. British Veterinary Journal 128, xxxvii-xl. 
HowARD, C. J. \& GouRLAY, R. N. (1973). Inhibition by normal rabbit sera of the growth of T-mycoplasma strains isolated from different animal species. Journal of General Microbiology 78, 227-239.

LANGFoRD, E. V. \& DoRwARD, W. J. (1969). A mycoplasma isolated from cattle with infectious bovine keratoconjunctivitis. Canadian Journal of Comparative Medicine 33, 275-279.

LANGFoRD, E. V. \& LEACH, R. H. (I973). Characterisation of mycoplasma isolated from infectious bovine keratoconjunctivitis, $M$. bovoculi sp. nov. Canadian Journal of Microbiology (in the Press).

LEACH, R. H. (1973). Further studies on classification of bovine strains of Mycoplasmatales, with proposals for new species, Acholeplasma modicum and Mycoplasma alkalescens. Journal of General Microbiology 75, 135-153.

MARMUR, J. (196I). A procedure for the isolation of deoxyribonucleic acid from microorganisms. Journal of Molecular Biology 3, 208-218.

MARMUR, J. \& DoTY, P. (I962). Determination of the base composition of deoxyribonucleic acid from its thermal denaturation temperature. Journal of Molecular Biology 5, 109-1 I8.

Rosendal, S. \& BLACK, F. T. (1972). Direct and indirect immunofluorescence of unfixed and fixed mycoplasma colonies. Acta pathologica et microbiologica scandinavica B 80, 615-622.

Subcommittee on the TAXONOMY of Mycoplasmatales (1972). Proposal for minimal standards for descriptions of new species of the order Mycoplasmatales. International Journal of Systematic Bacteriology 22, $184-188$.

Taylor-Robinson, D., Purcell, R. H., Wong, D. C. \& Chanock, R. M. (1966). A colour test for the measurement of antibody to certain mycoplasma species based upon the inhibition of acid production. Journal of Hygiene 64, 91-104. 